Cahiers $d u$ MONDE RUSSE

\section{Cahiers du monde russe}

Russie - Empire russe - Union soviétique et États indépendants

\title{
Jean-François Fayet, VOKS. Le laboratoire helvétique, Histoire de la diplomatie culturelle soviétique dans l'entre-deux-guerres
}

\section{Sophie Cœuré}

\section{(2) OpenEdition}

1 Journals

\section{Édition électronique}

URL : http://journals.openedition.org/monderusse/8292

DOI : $10.4000 /$ monderusse. 8292

ISSN : $1777-5388$

Éditeur

Éditions de l'EHESS

\section{Édition imprimée}

Date de publication : 1 octobre 2015

Pagination : 899-900

ISBN : 978-2-7132-2507-9

ISSN : $1252-6576$

\section{Référence électronique}

Sophie Cœuré, « Jean-François Fayet, VOKS. Le laboratoire helvétique, Histoire de la diplomatie culturelle soviétique dans l'entre-deux-guerres », Cahiers du monde russe [En ligne], 56/4 | 2015, mis en ligne le 01 octobre 2015, Consulté le 25 septembre 2020. URL : http://journals.openedition.org/ monderusse/8292 ; DOI : https://doi.org/10.4000/monderusse.8292 


\title{
Jean-François Fayet, VOKS. Le laboratoire helvétique, Histoire de la diplomatie culturelle soviétique dans l'entre-deux-guerres
}

\author{
Sophie Cœuré
}

\section{RÉFÉRENCE}

Jean-François FAYET, VOKS. Le laboratoire helvétique, Histoire de la diplomatie culturelle soviétique dans l'entre-deux-guerres, Genève : Georg Editeur, 2014, 598 p.

1 Le titre et le sous-titre du magistral ouvrage de Jean-François Fayet disent d'emblée la tension qui le traverse. VOKS. Le laboratoire helvétique se veut à la fois une réflexion synthétique sur la diplomatie culturelle soviétique dans l'entre-deux-guerres, et une analyse détaillée $\mathrm{du}$ cas suisse. L'expérience de l'auteur et l'impressionnant dépouillement documentaire effectué tant en Suisse qu'à Moscou avec l'appui du Fonds national suisse pour la recherche scientifique lui autorisaient cet ambitieux projet. Le plan retenu reprend une tripartition désormais classique présentant "l'émission » depuis Moscou, puis les relais organisationnels et personnels dans les «États bourgeois ", enfin la production culturelle de l'URSS et sa réception.

2 La singularité de la Suisse, siège de nombreuses organisations internationales, dont le Comité international de la Croix-Rouge (CICR), s'impose assurément dès la révolution d'Octobre. L'imbrication entre diplomatie officielle ou para-officielle et humanitaire permettra à Sergej Bagockij, médecin social-démocrate réfugié avec Lenin en Suisse en 1914, parti dans le dernier train qui rejoint la Russie révolutionnaire en décembre 1917, puis envoyé en Suisse pour une mission d'assistance aux soldats russes (déserteurs venus de France ou évadés des camps allemands ou autrichiens), de demeurer vingt ans en Suisse. Après l'expulsion de la mission Berzine et la rupture des relations 
diplomatiques, c'est Bagockij qui, dans une configuration politique retracée en détail par l'auteur, se trouvera finalement être à la fois le représentant en Suisse de la Croix-Rouge et le relais de la Société pour les relations culturelles avec l'étranger (VOKS - Vsesojuznoe Obščestvo Kul'turnoj Svjazi s zagranicej). Fondée en 1925 à Moscou, dans le contexte précisément d'une interaction entre la mobilisation internationale d'aide aux victimes de la famine en Russie et une diplomatie d'influence plus large, la VOKS s'impose dans l'entre-deux-guerres comme le principal vecteur d'une politique inventive. Déployée à l'échelle internationale, elle a pour objectif de diffuser une image positive et contrôlée de l'Union soviétique, comme l'ont montré depuis une vingtaine d'années de nombreux travaux, dont ceux de J.-F. Fayet lui-même.

Des pages éclairantes sont consacrées au rôle ambigu de Bagockij. L'unique représentant de l'URSS en Suisse dépasse sa mission culturelle et humanitaire pour faire fonction de consul, de représentant commercial, et sans doute, même si les sources manquent, de contact pour les services d'espionnage et de surveillance politique à l'étranger. Il parvient habilement à jouer de ses contacts dans les milieux internationaux, sans réussir à pallier un anticommunisme croissant, voire " hystérique ». Celui-ci est marqué par la surveillance, la censure, l'interdiction, dans les années 1930, aux communistes d'occuper un emploi fédéral, puis l'interdiction du PC dans plusieurs cantons, et par l'activisme de l'Entente internationale anticommuniste (EIA) basée à Genève.

4 L'action de la VOKS en Suisse est replacée dans un contexte soviétique où la politique générale de " séduction » des Occidentaux, la création de réseaux de médiateurs, mais aussi les enjeux économiques de l'exportation culturelle sont l'objet d'une féroce concurrence entre des organismes de statuts divers dans l'État-parti (Intourist, Sovkino, Amis de l'URSS, Secours ouvrier international, etc.). Le point commun entre les relais de la VOKS en Suisse, présentés en détail par J.-F. Fayet, est le décalage entre l'ambition affichée et la modestie des résultats. La Société d'études documentaires sur la Russie contemporaine, la Société pour les relations intellectuelles et scientifiques entre la Suisse et l'URSS, Das Neue Russland, le groupe ARPLAN, l'Association pour la promotion des relations commerciales entre la Suisse et l'URSS, les Amis de l'Union soviétique (puis Association Suisse-URSS), la Société Suisse-Russie d'informations économiques et culturelles, sont autant de micromilieux intéressants en eux-mêmes, par le contenu de leur philosoviétisme, par les personnalités qui les animent et par leurs interactions avec une partie de l'émigration russe en Suisse. Aucun ne parvient cependant à toucher au-delà de quelques centaines, quelques milliers de personnes au plus, alors que l'EIA, les Russes « blancs » et les ré-émigrants comme Pierre Gilliard, précepteur des enfants du tsar, multiplient les publications.

5 Dès lors, l'inventaire exhaustif des produits culturels diffusés en Suisse (par l'intermédiaire de la VOKS ou non) éclaire davantage l'image de soi que souhaite porter l'URSS qu'une demande locale. L'offre soviétique - éditions, bulletins, articles, expositions, photos et films, émissions de radio - est la même que celle qui est diffusée sans réciprocité dans tout l'Occident " bourgeois ». Elle est marquée par l'évolution d'une image défensive vers une affirmation orgueilleuse de la puissance socialiste, et par une présence croissante des thématiques industrielles et sociales. La spécificité suisse se lit dans les difficultés d'organisation qui expliquent le faible nombre de conférenciers soviétiques en Suisse et de voyageurs helvètes en URSS, et dans les réticences de la réception (malgré l'exception passionnante de la bibliothèque de 
Nikolaj Rubakin), même dans les milieux socialistes ou liés aux mouvements d'émancipation populaire. Ni les masses, ni les intellectuels de renom ne sont mobilisés.

L'ouvrage de Jean-François Fayet vient donc compléter très utilement le puzzle de la diplomatie culturelle soviétique. Si « laboratoire » il y eut, ce fut davantage dans les interactions de cette politique d'influence en Suisse avec le philosoviétisme européen (français et allemand surtout, en relation avec la complexité du paysage fédéral alémanique et romand, mais aussi internationaliste, incarné par Willi Münzenberg), et avec la diplomatie soviétique en Europe, notamment dans les organisations internationales où se déploie un véritable " entrisme ». Au moment où Bagockij est rappelé en URSS, en 1937 (il échappera aux purges et se reconvertira comme auteur d'articles de vulgarisation médicale), l'incapacité du philosoviétisme helvétique à se dissocier de l'anticommunisme intérieur - contrairement à ce qui se passe en France ou en Allemagne avant 1933 par exemple - est consommée. La reconnaissance de l'URSS par la Suisse en 1946 ne pourra inverser la tendance.

\section{AUTEURS}

\section{SOPHIE CEUUÉ}

Université Paris 7 Denis Diderot, ICT EA 337 